\title{
The Impact of Restriction-Modification Systems on Mating in Haloferax volcanii
}

\author{
Matthew Ouellette ${ }^{1,2,3 \dagger}$, Andrea M. Makkay ${ }^{1, \dagger}$, Artemis S. Louyakis ${ }^{1, \dagger}$, Uri Gophna ${ }^{4}$, J. Peter Gogarten ${ }^{1}$, and \\ R. Thane Papke1,*
}

${ }^{1}$ Department of Molecular and Cell Biology, University of Connecticut, Storrs, Connecticut, USA

${ }^{2}$ The Forsyth Institute, Cambridge, Massachusetts, USA

${ }^{3}$ Department of Oral Medicine, Infection and Immunity, Harvard School of Dental Medicine, Boston, Massachusetts, USA

${ }^{4}$ The George S. Wise Faculty of Life Sciences, Tel Aviv University, Tel Aviv Israel

* Correspondence: thane@uconn.edu

$\dagger$ These authors contributed equally.

\begin{abstract}
Halobacteria have been observed to be highly recombinogenic, frequently exchanging genetic material. Several barriers to mating in the Halobacteria have been examined, such as CRISPR-Cas, glycosylation, and archaeosortases, but these are low barriers that do not drastically reduce the recombination frequency. Another potential barrier could be restriction-modification (RM) systems, which cleave DNA that is not properly methylated, thus limiting the exchange of genetic material between cells which do not have compatible RM systems. In order to examine the role of RM systems on limiting recombination in the Halobacteria, the impact of RM systems on cellto-cell mating in Haloferax volcanii, a well-characterized method of genetic exchange and recombination in a halobacterial species, was examined. Strains which possessed all naturally-occurring RM system genes in $H$. volcanii $\left(\mathrm{RM}^{+}\right)$and strains without these $\mathrm{RM}$ systems $(\Delta \mathrm{RM})$ were mated together to compare the efficiency of gene transfer between RM-compatible strains and RM-incompatible strains. The results indicated that mating RMincompatible strains together resulted in a decrease in gene transfer efficiency compared to mating RM-compatible strains together, suggesting that RM systems limit mating in $H$. volcanii, but do not act as absolute barriers to recombination. Therefore, RM systems are low barriers to recombination in the Halobacteria, with RM-incompatible strains exchanging genetic material at a lower frequency than those with compatible RM systems, similar to other low recombination barriers in the Halobacteria.
\end{abstract}

Keywords: restriction, selfish genes, gene transfer, HGT, archaea, haloarchaea, mating

\section{Introduction}

In Bacteria and Archaea, distantly related organisms can exchange genetic material through horizontal gene transfer (HGT) and recombination. Many different strategies exist to allow for horizontal transfer of genetic material (Blakely, 2015). One method is natural transformation, where extracellular DNA is acquired via natural competence systems (Chen and Dubnau, 2004). Gene transfer can also occur via transduction, where bacteriophages transfer DNA between host cells (Touchon et al., 2017). Cells can also transfer genetic material via conjugation, where cells come into contact with each other and transfer plasmid DNA and integrative conjugal elements between each other, usually through specific structures such as a type IV pilus (Banuelos-Vazquez et al., 2017). Newly acquired genetic material which is not self-replicating is incorporated into the host's genome via homologous recombination, in which the DNA is integrated at homologous sites in the genome (Rocha et al., 2005). Although gene transfer can occur between species of distant lineages, barriers to exchange do exist which can prevent transfer between certain species. Some of these barriers are physiological in nature (Thomas and Nielsen, 2005), such as surface exclusion 
which limits conjugation by preventing pilus formation and DNA transfer between the cells (Arutyunov and Frost, 2013), host range limitations of transferred plasmids (Hulter et al., 2017), or the lack of DNA uptake signals in eDNA which prevents its use by naturally competent cells (Smith et al., 1999; Spencer-Smith et al., 2016). Barriers to recombination can result in HGT being more likely to occur among more closely related strains and species over transfer events between more distantly-related species (Andam and Gogarten, 2011).

Restriction-modification (RM) systems can also potentially act as barriers to gene transfer. RM systems consist of a restriction endonuclease (REase) and a DNA methyltransferase (MTase) which both recognize the same target sequence of DNA. The MTase will methylate a base at the target site, whereas the REase will cleave the site if it is not methylated (Ershova et al., 2015). These systems act as defense mechanisms for their host organisms, in which potentially harmful foreign DNA which is not properly methylated is cleaved by the REase while the host's own genome is protected due to methylation (Bickle and Kruger, 1993; Tock and Dryden, 2005). The ability of these systems to restrict foreign DNA could allow them to limit genetic exchange between species, thus potentially driving the diversification of microbial populations (Erwin et al., 2008; Budroni et al., 2011). Studies have demonstrated that RM systems can limit conjugal transfer of plasmids (Roer et al., 2015), and that they can limit the size of recombinant DNA fragments that are obtained via natural transformation (Lin et al., 2009).

Genetic recombination has been observed to occur frequently in several representatives of the halophilic archaeal class Halobacteria. In a study by Papke et al. (2007), Halorubrum strains isolated from saltern ponds in Spain and a hypersaline lake in Algeria were observed to cluster $(<1 \%$ DNA sequence divergence for five housekeeping genes) into three major phylogroups, with sequence diversification being driven primarily by recombination within the phylogroups rather than mutations. In a study by Fullmer et al. (2014), Halorubrum isolates from a hypersaline lake in Iran were observed to cluster into distinct phylogroups, with each group sharing an average nucleotide identity (ANI) of greater than $98 \%$. Recombination was also observed to occur frequently within the phylogroups, but at a lower rate between the phylogroups (Fullmer et al., 2014). Because recombination is more frequent between closely-related Halorubrum spp. strains, and less so with more distantly related species, barriers to gene flow limit genetic exchange, possibly resulting in genetically isolated populations and the diversification of haloarchaeal populations.

One mechanism of gene transfer in the Halobacteria is cell-to-cell mating, which has been characterized in Haloferax volcanii (Rosenshine et al., 1989). In this process, the cells come together and fuse into a heterodiploid state which contains the genetic material of both parental cells. This state allows for gene transfer and recombination between the parental cells. After genetic exchange, the cells will separate into hybrids of the parental strains (Rosenshine et al., 1989; Ortenberg et al., 1998; Naor et al., 2012). This process appears to have a low species barrier. In a study by Naor et al. (2012), H. volcanii was mated with the closely-related species Haloferax mediterranei, resulting in successful hybrids. However, the interspecies mating efficiency was observed to be lower than intraspecies mating events, suggesting that barriers to recombination exist which limit interspecies mating events between $H$. volcanii and $H$. mediterranei. One barrier to mating is CRISPR-Cas systems, which consist of short, repeated, spacer sequences acquired from foreign genetic elements that act as immunity systems for the host (Barrangou et al., 2007). These spacer sequences are used to produce RNAs known as crRNAs, which interact with Cas proteins to target and degrade invasive, foreign elements (Koonin et al., 2017). CRISPR-Cas systems have been identified in halobacterial species such as H. volcanii and H. mediterranei (Li et al., 2013; Maier et al., 2019), and research has indicated that these systems can limit interspecies mating between $H$. volcanii and $H$. mediterranei when the chromosome of one species is designed to be targeted by the partner species, although they do not act as total barriers to recombination (Turgeman-Grott et al., 2019). The glycosylation of surface glycoproteins has also been observed to affect mating in $H$. volcanii. A study by Shalev et al. (2017) tested the mating efficiency of $H$. volcanii mutant with the glycosylation genes $a g l B$ and $a g l 15$, and observed a dramatic decrease in mating efficiency when the deletion mutants were mated together, indicating that proper glycosylation is required for mating. However, mating the deletion mutant with their parental strains resulted in a less notable decrease in mating, suggesting that glycosylation limits mating between strains with different glycosylation patterns, but is likely not an absolute barrier to recombination (Shalev et al., 2017). Modification of surface proteins by archaeosortases has also been observed to affect mating. A study by Abdul Halim et al. (2013) examined the mating efficiency of a $H$. volcanii strain with the archaeosortase gene artA deleted, and observed that mating decreased in the deletion mutant 
compared to the parental strain, but was not a total barrier to recombination. Overall, CRISPR-Cas, glycosylation, and archaeosortases act as low barriers to mating, but do not prohibit recombination completely.

Another possible barrier to mating in the $H$. volcanii might be RM systems. Studies have characterized a few of these systems in $H$. volcanii, including a Type I RM system which targets the motif GCABN 6 VTGC (Ouellette et al., 2015; Ouellette et al., 2018). A Type IV REase known as Mrr has also been characterized in $H$. volcanii, and has been observed to reduce transformation efficiency on GATC-methylated plasmids (Holmes et al., 1991; Allers et al., 2010). However, the overall role of these systems on cell-to-cell mating and recombination has not been examined in detail. In this study, derivatives of the $H$. volcanii RM system deletion strain from Ouellette $e t$ al. (2018) were used in mating experiments to determine the impact of RM systems on cell-to-cell mating in $H$. volcanii.

\section{Materials and Methods}

\subsection{Strains and Growth Conditions}

All strains and plasmids used in this study are recorded in Table 1. Haloferax volcanii strains were grown in either rich undefined medium (Hv-YPC) or selective undefined medium ( $\mathrm{Hv}-\mathrm{Ca}$ ) developed by Allers et al. (2004) and listed in the Halohandbook (Dyall-Smith, 2009). Media was supplemented with uracil $(50 \mu \mathrm{g} / \mathrm{mL}$ ) and 5fluoroorotic acid (5-FOA) $(50 \mu \mathrm{g} / \mathrm{mL})$ as needed to grow $\triangle p y r E 2$ strains. For $\triangle \operatorname{trp} A$ strains, the media was supplemented with tryptophan $(50 \mu \mathrm{g} / \mathrm{mL})$ as needed, whereas thymidine $(40 \mu \mathrm{g} / \mathrm{mL})$ and hypoxanthine $(40 \mu \mathrm{g} / \mathrm{mL})$ were supplemented as needed when growing $\triangle h d r B$ strains. The strains were grown at $42{ }^{\circ} \mathrm{C}$ while shaking at 200 rpm. Escherichia coli strains were grown at $37^{\circ} \mathrm{C}$ while shaking at $200 \mathrm{rpm}$ in lysogeny broth (LB), with ampicillin $(100 \mu \mathrm{g} / \mathrm{mL})$ added to the medium as needed.

Table 1. List of plasmids and strains used in this study.

\begin{tabular}{|c|c|c|}
\hline Strain/Plasmid Name & Description & Source \\
\hline H. volcanii $\mathrm{H} 53$ & $\begin{array}{c}\triangle p y r E 2 \triangle \operatorname{trp} A \text { uracil and tryptophan auxotrophic } \\
\text { strain of wild-type } H \text {. volcanii }\end{array}$ & (Allers et al., 2004) \\
\hline H. volcanii $\mathrm{H} 98$ & $\begin{array}{l}\triangle p y r E 2 \triangle h d r B \text { uracil, thymidine, and hypoxanthine } \\
\text { auxotrophic strain of wild-type } H \text {. volcanii }\end{array}$ & (Allers et al., 2004) \\
\hline H. volcanii $\Delta \mathrm{RM}$ & $\begin{array}{c}\text { Deletion strain of RM genes } H V O \_0794, \text { rmeRMS } \\
H V O \_A 0006, H V O_{-} A 0074, H V O \_A 0079, \text { and } \\
H V O \_A 0237 \text { derived from a } \triangle p y r E 2 \text { uracil } \\
\text { auxotrophic strain of } H . \text { volcanii }\end{array}$ & (Ouellette et al., 2018) \\
\hline H. volcanii $\mathrm{RM} \triangle \operatorname{trp} A$ & $\begin{array}{l}\Delta \operatorname{trp} A \text { tryptophan auxotrophic strain derived from } \\
\qquad \mathrm{RM}\end{array}$ & This study \\
\hline H. volcanii RM $\Delta h d r B$ & $\begin{array}{c}\Delta h d r B \text { thymidine and hypoxanthine auxotrophic } \\
\text { strain derived from } \Delta \mathrm{RM}\end{array}$ & This study \\
\hline E. coli $\mathrm{HST} 08$ & E. coli cloning strain & Clontech, Cat. \# 636763 \\
\hline pTA95 & Plasmid used to delete $\operatorname{trp} A$ gene & (Allers et al., 2004) \\
\hline pTA155 & Plasmid used to delete $h d r B$ gene & (Allers et al., 2004) \\
\hline
\end{tabular}

\subsection{Deletion of trpA and hdrB Genes from $\triangle R M$ Strain}

Plasmids pTA95 and pTA155 were used to delete $\operatorname{trp} A$ and $h d r B$, respectively, from $H$. volcanii strain $\triangle \mathrm{RM}$. These plasmids were transformed into the $\triangle \mathrm{RM}$ strain using the polyethylene glycol (PEG)-mediated transformation protocol from the Halohandbook (Dyall-Smith, 2009), with resulting transformants being plated on Hv-Ca for 5-7 days. Screening for pop-ins was performed via colony PCR with screening primers (Table 2) and gel 
electrophoresis for visualization. Pop-outs were obtained by plating confirmed pop-ins on Hv-Ca plates with 5-FOA, uracil, tryptophan, thymidine, and hypoxanthine. Successful pop-outs were identified via replica plating onto Hv-Ca plates with uracil but without tryptophan, thymidine, or hypoxanthine, as well as via the colony PCR screening method used to detected pop-ins.

Table 2. List of primers used in this study.

\begin{tabular}{ccc}
$\begin{array}{c}\text { Primer } \\
\text { Name }\end{array}$ & Primer Sequence & Primer Description \\
\hline dTrp5F & 5'-GCTCTAGAACGCGCTCGGGCAGGTCTTACTGG -3' & $\begin{array}{c}\text { Used to screen for deletion of trpA } \\
\text { (Primer designs from Allers } \text { et al., }\end{array}$ \\
dTrp3R & 5 '-CCGGTGAGTCTCTAGACGTTTTCGTCCG -3' & (2004)) \\
d_hdrBF & 5 '-TCCCGCCGTGTCACTACA -3' & Used to screen for deletion of $h d r B$ \\
d_hdrBR & 5'-ACGTTCACGACGGTACAGGG -3' & \\
\hline
\end{tabular}

\subsection{Mating $H 53$ and $H 98$ Strains with $R M \Delta \operatorname{trpA}$ and $R M \Delta \mathrm{hdrB}$ Strains}

Experiments were set up following a mating protocol adapted from Naor et al. (2012). Cultures of H53, $\mathrm{H} 98$, RM $\triangle \operatorname{trp} A$, and RM $\triangle h d r B$ were grown in triplicate across three experiments (9 replicates total) to an $\mathrm{OD}_{600}$ of $\sim 1-1.1$, with $2 \mathrm{~mL}$ of two different cultures applied to $0.2 \mu \mathrm{m}$ filters. The cultures were mixed in the following combinations: $\mathrm{H} 53 \times \mathrm{H} 98, \mathrm{H} 53 \times \mathrm{RM} \Delta h d r B, \mathrm{RM} \Delta \operatorname{trp} A \times \mathrm{H} 98$, and RM $\Delta \operatorname{trp} A \times \mathrm{RM} \Delta h d r B$. The resulting filters were then placed on plates of $\mathrm{Hv}-\mathrm{Ca}$ with uracil, tryptophan, thymidine, and hypoxanthine and incubated at $42{ }^{\circ} \mathrm{C}$ for 2 days. The filters were then transferred to $2-\mathrm{mL}$ tubes containing $1 \mathrm{~mL}$ of liquid $\mathrm{Hv}-\mathrm{Ca}$ medium and shaken at $200 \mathrm{rpm}$ for $\sim 1$ hour to resuspend the cells in the medium. The resuspended cultures were then diluted and plated onto Hv-Ca plates with uracil to determine the number of recombinants, and Hv-Ca plates with uracil, tryptophan, thymidine, and hypoxanthine to determine the total number of viable cells. The plates were incubated at $37^{\circ} \mathrm{C}$ for 1 week. The number of recombinants was divided by the total number of viable cells to calculate the mating efficiency of each mated combination. Mann-Whitney $\mathrm{U}$ tests were performed in R with the package ggpubr v0.2.1 (Kassambara, 2018). A boxplot was constructed in R using the package ggplot2 v3.2.0 (Wickham, 2016).

\section{Results}

\section{Mating Efficiency is Lower When Mating RM-incompatible Strains}

In order to determine whether RM systems in $H$. volcanii can act as a barrier to mating, $H$. volcanii strains $\mathrm{H} 53$ and $\mathrm{H} 98$, which contained the full set of $\mathrm{RM}$ system genes $\left(\mathrm{RM}^{+}\right)$, and $\triangle \mathrm{RM}$ derivative strains which were missing RM system genes (RM $\triangle \operatorname{trp} A, \mathrm{RM} \triangle h d r B$ ) were mated together (Figure 1). Each strain was mated with a partner strain with a matching set of RM genes (RM-compatible; H53 $\times \mathrm{H} 98, \mathrm{RM} \Delta \operatorname{trp} A \times \mathrm{RM} \Delta h d r B$ ) and a partner strain without matching RM gene sets (RM-incompatible; H53 $\times$ RM $\Delta h d r B, \mathrm{RM} \Delta \operatorname{trp} A \times \mathrm{H} 98$ ). In each mating event, one strain is a tryptophan auxotroph $(\triangle \operatorname{trp} A)$ and the other strain is a thymidine auxotroph $(\Delta h d r B)$. Therefore, by mating the strains together and plating them on selective plates without tryptophan or thymidine, recombinants can be selected which contain both $\operatorname{trp} A$ and $h d r B$ from both parental strains, and mating efficiency can be determined by calculating the number of colonies on the selective plates divided by the total number of viable cells for each mating event.

The results indicate that mating H53 with $\mathrm{H} 98(\mathrm{H} 53 \times \mathrm{H} 98)$ had an average mating efficiency of $1.6 \times 10^{-4}$. In comparison, mating $\mathrm{H} 53$ with $\mathrm{RM} \Delta h d r B(\mathrm{H} 53 \times \mathrm{RM} \Delta h d r B)$ resulted in an average mating efficiency of $5.2 \times$ $10^{-5}$, representing a $\sim 66 \%$ decrease from $\mathrm{H} 53 \times \mathrm{H} 98$. The difference between these efficiencies was supported as significant by Mann-Whitney $\mathrm{U}(p=0.004)$. When mating RM $\triangle \operatorname{trp} A$ with $\mathrm{H} 98$ (RM $\Delta \operatorname{trp} A \times \mathrm{H} 98$ ), the average mating efficiency was $3.7 \times 10^{-5}$, representing a $\sim 77 \%$ decrease from $\mathrm{H} 53 \times \mathrm{H} 98$. This was a significant difference supported by Mann-Whitney $\mathrm{U}(p=0.001)$. 


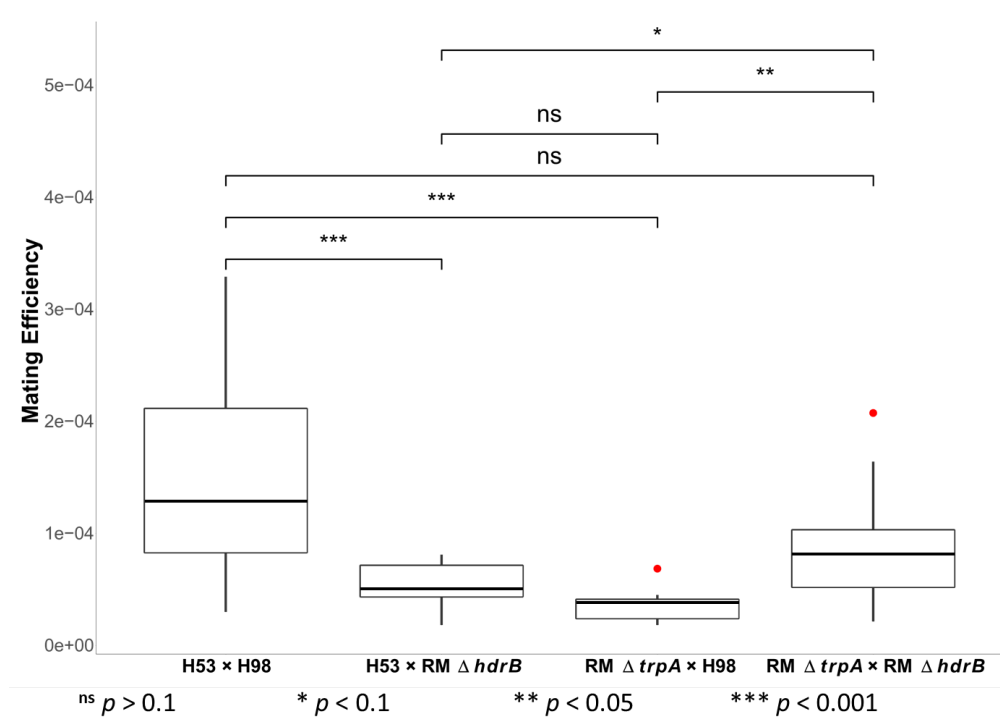

Figure 1. Box plot for mating efficiencies of $H$. volcanii strains $\mathrm{H} 53$ and H98 with RM system genes $\left(\mathrm{RM}^{+}\right)$and $\triangle \mathrm{RM}$ derivative strains without $\mathrm{RM}$ systems (RM $\left.\Delta \operatorname{trp} A, \mathrm{RM} \Delta h d r B\right)$. Mating crosses between RM-compatible strains $(\mathrm{H} 53 \times \mathrm{H} 98, \mathrm{RM} \Delta \operatorname{trp} A \times \mathrm{RM} \Delta h d r B)$ and RMincompatible strains $(\mathrm{H} 53 \times \mathrm{RM} \Delta h d r B, \mathrm{RM} \triangle \operatorname{trp} A \times \mathrm{H} 98)$ were performed. Mating efficiency is expressed as the average number of colonies on selective plates divided by the total number of viable cells of each mating cross performed in triplicate for three experiments ( 9 replicates total). Red dots represent outliers. The $p$-values are from Mann-Whitney U tests of the differences between each mating cross.

When mating RM $\Delta \operatorname{trp} A$ with $\mathrm{RM} \Delta h d r B(\mathrm{RM} \Delta \operatorname{trp} A \times \mathrm{RM} \Delta h d r B)$, the average mating efficiency was observed to be $9.2 \times 10^{-5}$. This was a $\sim 3 \%$ decrease in mating efficiency from $\mathrm{H} 53 \times \mathrm{H} 98$, but this difference was not significant according to Mann-Whitney $\mathrm{U}(p=0.14)$. The mating efficiency increased from $\mathrm{H} 53 \times \mathrm{RM} \Delta h d r B$ by $\sim 70 \%$. However, the difference was not strongly supported as significant by Mann-Whitney $\mathrm{U}(p=0.09)$. The mating efficiency of RM $\Delta \operatorname{trp} A \times \mathrm{RM} \Delta h d r B$ increased by $\sim 149 \%$ from RM $\Delta \operatorname{trp} A \times \mathrm{H} 98$, and the differences were supported as significant via Mann-Whitney $\mathrm{U}(p=0.02)$. A difference was also observed between the mating efficiency of the RM-incompatible mating events, with RM $\Delta \operatorname{trp} A \times \mathrm{H} 98$ exhibiting a $\sim 33 \%$ lower mating efficiency than $\mathrm{H} 53 \times \mathrm{RM} \Delta h d r B$. However, this difference was not supported as significant by Mann-Whitney $\mathrm{U}(p=0.11)$. Overall, the results indicate that mating efficiency between RM-compatible strains is higher than the mating efficiency between RM-incompatible strains in $H$. volcanii.

\section{Discussion}

This study provides evidence that RM systems might act as post-fusion barriers to recombination in $H$. volcanii. When RM-compatible strains were mated together, such as H53 with H98 and RM $\Delta \operatorname{trp} A$ with RM $\triangle h d r B$, the recombination efficiencies were similar to each other. The average mating efficiencies when crossing the RMcompatible strains were both close to the $1 \times 10^{-4}$ intraspecies mating efficiency for $H$. volcanii observed by Naor $e t$ al. (2012), with $\mathrm{H} 53 \times \mathrm{H} 98$ having an average mating efficiency of $\sim 1.6 \times 10^{-4}$ and $\mathrm{RM} \Delta \operatorname{trp} A \times \mathrm{RM} \Delta h d r B$ having an average mating efficiency of $\sim 9.2 \times 10^{-5}$. However, when RM-incompatible strains were mated together, such as $\mathrm{H} 53 \times \mathrm{RM} \triangle h d r B$ or RM $\Delta \operatorname{trp} A$ with $\mathrm{H} 98$, the mating efficiencies were observed to be lower than mating between RM-compatible strains. This difference indicates that when cells do not have compatible sets of RM systems, they recombine less frequently, likely due to the RM systems from $\mathrm{RM}^{+}$cells cleaving DNA from $\triangle \mathrm{RM}$ partner cells which is not properly methylated at recognition sites of the RM systems, thus preventing recombination from occurring. 
RM systems have been observed to limit conjugation events in bacteria. In a study by Roer et al. (2015), for example, conjugation was observed to be limited in E. coli by the RM system EcoKI when using plasmids with unmethylated EcoKI target sites, although they are not a major barrier to conjugal transfer. A $\sim 85 \%$ reduction in transfer rate was observed when unmethylated plasmids were transferred into a recipient strain with an active EcoKI system in comparison to the rate when using a recipient strain with a deactivated EcoKI system (Roer et al., 2015). This reduction in E. coli conjugation is slightly higher than the $\sim 66-77 \%$ decrease in mating efficiency observed when mating RM-incompatible strains together, suggesting that RM systems have a slightly lower impact on cell-tocell mating in $H$. volcanii than they do on conjugation in E. coli.

A few studies have also suggested that RM systems can limit recombination as well. Phylogenetic studies in Haemophilus influenzae and Neisseria meningitidis have suggested RM systems could act as barriers to recombination and drive population diversification (Erwin et al., 2008; Budroni et al., 2011). A Type III RM system in Staphylococcus aureus has also been demonstrated to prevent natural transformation on DNA from other bacterial species such as E. coli (Corvaglia et al., 2010). However, other studies have indicated that DNA cleaved by RM systems are still able to recombine, and that RM systems only limit the size of recombined DNA fragments (Vasu and Nagaraja, 2013). A study by Chang and Cohen (1977) indicated that the REase of RM system EcoRI was able to mediate site-specific recombination in E. coli. A study of natural transformation in Helicobacter pylori by Lin et al. (2009) indicated that RM systems limited the size of fragments imported during transformation, but did not prevent recombination of those fragments. The decreased mating between RM-incompatible strains observed in this study suggests that RM systems act to reduce recombination in H. volcanii rather than just limit fragment size of DNA during mating, and might be more effective if the methylation site were highly distributed around the chromosome or in the middle of our genetic markers.

The results also indicate that the RM $\triangle \operatorname{trp} A$ and RM $\triangle h d r B$ strains, when mated together, had a slightly decreased mating efficiency compared to when H53 and H98 were mated together. This result suggests that strains derived from $\triangle \mathrm{RM}$, which are missing active RM systems, are less efficient at mating than $\mathrm{RM}^{+}$strains $\mathrm{H} 53$ and H98, which would indicate the RM systems have an important role in facilitating recombination. However, this difference was not strongly supported by Mann-Whitney $\mathrm{U}$, so it is possible that this difference was due to chance. Also, the observation of an increase in mating efficiency when compared to H53 $\times$ RM $\Delta h d r B$ and RM $\Delta \operatorname{trp} A \times \mathrm{H} 98$ suggests that, even if the $\triangle \mathrm{RM}$ strains themselves have a lower mating efficiency, RM-incompatibility between strains also results in reduced mating efficiency.

In H. volcanii, there are two major methylated motifs throughout the genome: the $\mathrm{m} 4 \mathrm{C}$ motif $\mathrm{C}^{\mathrm{m} 4} \mathrm{TAG}$ and the m6A motif GCA ${ }^{\mathrm{m} 6} \mathrm{BN}_{6} \mathrm{VTGC}$ (Ouellette et al., 2015). The $\mathrm{C}^{\mathrm{m} 4} \mathrm{TAG}$ motif is methylated by the orphan MTase HVO_0794 and the GCA ${ }^{\mathrm{m} 6} \mathrm{BN}_{6}$ VTGC motif is methylated by the Type I RM system RmeRMS (Ouellette et al., 2018). Since HVO_0794 is an orphan MTase and is not associated with a RM system, it is unlikely to have an impact on mating efficiency and recombination. The most likely candidate for reducing mating between RMincompatible strains in H. volcanii is the RmeRMS system. In the $\Delta \mathrm{RM}$ strain and its derivatives, the genome is missing the operon that encodes the RmeRMS system, and is unmethylated at its target sites (Ouellette et al., 2018). Therefore, the target sites of RmeRMS would be exposed to cleavage when $\triangle \mathrm{RM}$ derivative strains are mated with strains $\mathrm{H} 53$ or H98, which have the RmeRMS system. While $H$. volcanii also has the Type IV REase Mrr, which limits transformation efficiency with GATC-methylated plasmids from E. coli (Holmes et al., 1991; Allers et al., 2010), this REase has not been demonstrated to cleave methylated $H$. volcanii DNA and is unlikely to affect mating and recombination. Therefore, the decrease in mating between RM-incompatible strains is likely the result of RmeRMS in the $\mathrm{RM}^{+}$strain cleaving unmethylated sites from the $\Delta \mathrm{RM}$ strain and, therefore, limiting recombination between the strains. However, examination of the $\operatorname{trp} A$ and $h d r B$ marker gene sequences, which are exchanged during mating, indicated that there are no RmeRMS sites located within those genes. The closest RmeRMS site to $\operatorname{trp} A$ is located $897 \mathrm{bp}$ upstream of the gene, and the closest site to $h d r B$ is located $6441 \mathrm{bp}$ upstream of the gene. This would suggest that RmeRMS could negatively impact recombination even when the restriction sites are distantly located from the genes of interest. One possible explanation is that RM-incompatibility between strains reduces the time that the cells can coexist after fusing together due to DNA cleavage, resulting the cells separating early from each other and, therefore, reducing chances for recombination between the cells. It is possible that, if the restriction sites were located closer to the genes of interest, or within the genes themselves, the mating efficiency between the RM-incompatible strains would decrease further. Since the RmeRMS site is located closer to trpA than 
$h d r B$, it is possible that recombination is more limited for $\operatorname{trp} A$ than $h d r B$. This may explain the difference in mating efficiency observed between the two RM-incompatible mating crosses. However, this difference was not supported as statistically significant. Future mating experiments using $\triangle \mathrm{RM}$ derivative strains complemented with the rmeRMS operon could confirm the role of this RM system in limiting mating in $H$. volcanii.

RM-incompatibility may also be an explanation for the lower interspecies mating efficiency observed between $H$. volcanii and $H$. mediterranei (Naor et al., 2012). According to the RM database REBASE (Roberts et al., 2015), H. mediterranei has only three RM-related genes (http://rebase.neb.com/cgi-bin/onumget?8920): a Type IV REase (Mrr), an orphan m4C CTAG MTase (M.Hme33500I), and an orphan m4C MTase which modifies the motif $\mathrm{HGC}^{\mathrm{m}}{ }^{\mathrm{W}}$ WCK (M.Hme33500II), also described recently (DasSarma et al., 2019). Since it has no Type I RM system analogous to RmeRMS in $H$. volcanii, its genome is unmethylated at the target sites of that RM system. Therefore, the genome of $H$. mediterranei is exposed to cleavage by the RmeRMS system when mating with $H$. volcanii, which could limit recombination. Interestingly, the interspecies mating efficiency observed by Naor $e t$ al. (2012) was $4.2 \times 10^{-5}$, which is between the mating efficiencies observed when crossing RM-incompatible strains $\left(\sim 5.2 \times 10^{-5}\right.$ for $\mathrm{H} 53 \times \mathrm{RM} \Delta h d r B$ and $\sim 3.7 \times 10^{-5}$ for RM $\left.\Delta \operatorname{trp} A \times \mathrm{H} 98\right)$. Genome sequencing of 10 hybrids also indicated that they were all $H$. mediterranei which had received genetic material from $H$. volcanii, indicating that genetic transfer during mating always occurred in one direction (from H. volcanii to H. mediterranei)(Naor et al., 2012). It is possible that the presence of RmeRMS in $H$. volcanii may prevent the transfer of genetic material from $H$. mediterranei to $H$. volcanii due to exposed RmeRMS sites. It is also possible that the lower interspecies mating efficiency is due to $H$. mediterranei containing CRISPR spacers which target the genome of $H$. volcanii, since interspecies mating efficiency is further reduced when a CRISPR is added to H. mediterranei which is specifically targeted by $H$. volcanii (Turgeman-Grott et al., 2019). Future interspecies mating experiments in which $H$. volcanii $\Delta \mathrm{RM}$ derivative strains are crossed with $H$. mediterranei could elucidate the impact of RM systems on mating efficiencies between these two species.

Although the Halobacteria are highly recombinogenic, distinct phylogroups have been observed even within the same geographic location (Papke et al., 2007; Fullmer et al., 2014). This suggests that there are barriers to recombination within the Halobacteria which limit interactions between phylogroups and allow for speciation to occur. Our results indicate that when RM systems are incompatible between mating strains of $H$. volcanii, there is a decrease in mating efficiency. This RM-driven decrease in recombination suggests that strains of Halobacteria which have incompatible sets of RM systems might recombine less frequently in natural environments, resulting in the eventual divergence of incompatible strains. However, the results also indicate that RM systems are not a strong barrier to gene flow and are not very efficient in preventing mating between RM-incompatible strains, similar to CRISPR-Cas, glycosylation, and archaeosortases.

Author contributions: Conceptualization, R.T.P., A.M.M, and M.O.; Funding Acquisition, R.T.P. and J.P.G.; Formal Analysis, M.O., A.M.M. and A.S.L.; Methodology, M.O., A.M.M., and R.T.P; Writing-Original Draft, M.O. and R.T.P.; Writing—Review \& Editing, M.O., A.M.M., A.S.L., R.T.P., and J.P.G.

Funding: This work was supported through grants from the Binational Science Foundation (BSF 2013061), the National Science Foundation (NSF/MCB 1716046) within the BSF-NSF joint research program, and NASA exobiology (NNX15AM09G, and 80NSSC18K1533).

Conflicts of Interest: The authors declare no conflicts of interest. 


\section{References}

Abdul Halim, M.F., Pfeiffer, F., Zou, J., Frisch, A., Haft, D., Wu, S., Tolić, N., Brewer, H., Payne, S.H., and PašaTolić, L. (2013). Haloferax volcanii archaeosortase is required for motility, mating, and C-terminal processing of the S-layer glycoprotein. Molecular microbiology 88, 1164-1175.

Allers, T., Barak, S., Liddell, S., Wardell, K., and Mevarech, M. (2010). Improved strains and plasmid vectors for conditional overexpression of His-tagged proteins in Haloferax volcanii. Appl Environ Microbiol 76, 17591769 .

Allers, T., Ngo, H.P., Mevarech, M., and Lloyd, R.G. (2004). Development of additional selectable markers for the halophilic archaeon Haloferax volcanii based on the leuB and trpA genes. Appl Environ Microbiol 70, 943953.

Andam, C.P., and Gogarten, J.P. (2011). Biased gene transfer in microbial evolution. Nature Reviews Microbiology $9,543$.

Arutyunov, D., and Frost, L.S. (2013). F conjugation: back to the beginning. Plasmid 70, 18-32.

Banuelos-Vazquez, L.A., Torres Tejerizo, G., and Brom, S. (2017). Regulation of conjugative transfer of plasmids and integrative conjugative elements. Plasmid 91, 82-89.

Barrangou, R., Fremaux, C., Deveau, H., Richards, M., Boyaval, P., Moineau, S., Romero, D.A., and Horvath, P. (2007). CRISPR provides acquired resistance against viruses in prokaryotes. Science 315, 1709-1712.

Bickle, T.A., and Kruger, D.H. (1993). Biology of DNA restriction. Microbiol Rev 57, 434-450.

Blakely, G.W. (2015). "Mechanisms of Horizontal Gene Transfer and DNA Recombination," in Molecular Medical Microbiology. Elsevier), 291-302.

Budroni, S., Siena, E., Dunning Hotopp, J.C., Seib, K.L., Serruto, D., Nofroni, C., Comanducci, M., Riley, D.R., Daugherty, S.C., Angiuoli, S.V., Covacci, A., Pizza, M., Rappuoli, R., Moxon, E.R., Tettelin, H., and Medini, D. (2011). Neisseria meningitidis is structured in clades associated with restriction modification systems that modulate homologous recombination. Proc Natl Acad Sci U S A 108, 4494-4499.

Chang, S., and Cohen, S.N. (1977). In vivo site-specific genetic recombination promoted by the EcoRI restriction endonuclease. Proc Natl Acad Sci U S A 74, 4811-4815.

Chen, I., and Dubnau, D. (2004). DNA uptake during bacterial transformation. Nat Rev Microbiol 2, 241-249.

Corvaglia, A.R., François, P., Hernandez, D., Perron, K., Linder, P., and Schrenzel, J. (2010). A type III-like restriction endonuclease functions as a major barrier to horizontal gene transfer in clinical Staphylococcus aureus strains. Proceedings of the National Academy of Sciences 107, 11954-11958.

DasSarma, S., Fomenkov, A., DasSarma, S. L., Vincze, T., DasSarma, P., \& Roberts, R. J. (2019). Methylomes of Two Extremely Halophilic Archaea Species, Haloarcula marismortui and Haloferax mediterranei. Microbiology resource announcements, 8(27), e00577-19. 
Dyall-Smith, M. (2009). The Halohandbook: Protocols for Haloarchaeal Genetics Ver. 7.2 [Online]. Available: https://haloarchaea.com/halohandbook/ [Accessed September 6, 2013].

Ershova, A.S., Rusinov, I.S., Spirin, S.A., Karyagina, A.S., and Alexeevski, A.V. (2015). Role of restrictionmodification systems in prokaryotic evolution and ecology. Biochemistry (Mosc) 80, 1373-1386.

Erwin, A.L., Sandstedt, S.A., Bonthuis, P.J., Geelhood, J.L., Nelson, K.L., Unrath, W.C., Diggle, M.A., Theodore, M.J., Pleatman, C.R., Mothershed, E.A., Sacchi, C.T., Mayer, L.W., Gilsdorf, J.R., and Smith, A.L. (2008). Analysis of genetic relatedness of Haemophilus influenzae isolates by multilocus sequence typing. $J$ Bacteriol 190, 1473-1483.

Fullmer, M.S., Soucy, S.M., Swithers, K.S., Makkay, A.M., Wheeler, R., Ventosa, A., Gogarten, J.P., and Papke, R.T. (2014). Population and genomic analysis of the genus Halorubrum. Front Microbiol 5, 140.

Holmes, M.L., Nuttall, S.D., and Dyall-Smith, M.L. (1991). Construction and use of halobacterial shuttle vectors and further studies on Haloferax DNA gyrase. J Bacteriol 173, 3807-3813.

Hulter, N., Ilhan, J., Wein, T., Kadibalban, A.S., Hammerschmidt, K., and Dagan, T. (2017). An evolutionary perspective on plasmid lifestyle modes. Curr Opin Microbiol 38, 74-80.

Kassambara, A. (2018). ggpubr:'ggplot2'Based Publication Ready Plots (2018). R package version 0.2.

Koonin, E.V., Makarova, K.S., and Zhang, F. (2017). Diversity, classification and evolution of CRISPR-Cas systems. Current opinion in microbiology 37, 67-78.

Li, M., Liu, H., Han, J., Liu, J., Wang, R., Zhao, D., Zhou, J., and Xiang, H. (2013). Characterization of CRISPR RNA biogenesis and Cas6 cleavage-mediated inhibition of a provirus in the haloarchaeon Haloferax mediterranei. Journal of bacteriology 195, 867-875.

Lin, E.A., Zhang, X.S., Levine, S.M., Gill, S.R., Falush, D., and Blaser, M.J. (2009). Natural transformation of Helicobacter pylori involves the integration of short DNA fragments interrupted by gaps of variable size. PLoS Pathog 5, e1000337.

Maier, L.-K., Stachler, A.-E., Brendel, J., Stoll, B., Fischer, S., Haas, K.A., Schwarz, T.S., Alkhnbashi, O.S., Sharma, K., and Urlaub, H. (2019). The nuts and bolts of the Haloferax CRISPR-Cas system IB. RNA biology 16, 469-480.

Naor, A., Lapierre, P., Mevarech, M., Papke, R.T., and Gophna, U. (2012). Low species barriers in halophilic archaea and the formation of recombinant hybrids. Curr Biol 22, 1444-1448.

Ortenberg, R., Tchlet, R., and Mevarech, M. (1998). A model for the genetic exchange system of the extremely halophilic archaeon Haloferax volcanii. Microbiology and biogeochemistry of hypersaline environments 5, 331.

Ouellette, M., Gogarten, J.P., Lajoie, J., Makkay, A.M., and Papke, R.T. (2018). Characterizing the DNA methyltransferases of Haloferax volcanii via bioinformatics, gene deletion, and SMRT sequencing. Genes (Basel) 9.

Ouellette, M., Jackson, L., Chimileski, S., and Papke, R.T. (2015). Genome-wide DNA methylation analysis of Haloferax volcanii $\mathrm{H} 26$ and identification of DNA methyltransferase related PD-(D/E)XK nuclease family protein HVO_A0006. Front Microbiol 6, 251. 
Papke, R.T., Zhaxybayeva, O., Feil, E.J., Sommerfeld, K., Muise, D., and Doolittle, W.F. (2007). Searching for species in haloarchaea. Proc Natl Acad Sci U S A 104, 14092-14097.

Roberts, R.J., Vincze, T., Posfai, J., and Macelis, D. (2015). REBASE--a database for DNA restriction and modification: enzymes, genes and genomes. Nucleic Acids Res 43, D298-299.

Rocha, E.P., Cornet, E., and Michel, B. (2005). Comparative and evolutionary analysis of the bacterial homologous recombination systems. PLoS genetics 1 , e15.

Roer, L., Aarestrup, F.M., and Hasman, H. (2015). The EcoKI type I restriction-modification system in Escherichia coli affects but is not an absolute barrier for conjugation. J Bacteriol 197, 337-342.

Rosenshine, I., Tchelet, R., and Mevarech, M. (1989). The mechanism of DNA transfer in the mating system of an archaebacterium. Science 245, 1387-1389.

Shalev, Y., Turgeman-Grott, I., Tamir, A., Eichler, J., and Gophna, U. (2017). Cell surface glycosylation is required for efficient mating of Haloferax volcanii. Frontiers in microbiology 8, 1253.

Smith, H.O., Gwinn, M.L., and Salzberg, S.L. (1999). DNA uptake signal sequences in naturally transformable bacteria. Res Microbiol 150, 603-616.

Spencer-Smith, R., Roberts, S., Gurung, N., and Snyder, L.a.S. (2016). DNA uptake sequences in Neisseria gonorrhoeae as intrinsic transcriptional terminators and markers of horizontal gene transfer. Microb Genom 2, e000069.

Thomas, C.M., and Nielsen, K.M. (2005). Mechanisms of, and barriers to, horizontal gene transfer between bacteria. Nat Rev Microbiol 3, 711-721.

Tock, M.R., and Dryden, D.T. (2005). The biology of restriction and anti-restriction. Curr Opin Microbiol 8, 466472.

Touchon, M., Moura De Sousa, J.A., and Rocha, E.P. (2017). Embracing the enemy: the diversification of microbial gene repertoires by phage-mediated horizontal gene transfer. Curr Opin Microbiol 38, 66-73.

Turgeman-Grott, I., Joseph, S., Marton, S., Eizenshtein, K., Naor, A., Soucy, S.M., Stachler, A.-E., Shalev, Y., Zarkor, M., and Reshef, L. (2019). Pervasive acquisition of CRISPR memory driven by inter-species mating of archaea can limit gene transfer and influence speciation. Nature microbiology 4, 177.

Vasu, K., and Nagaraja, V. (2013). Diverse functions of restriction-modification systems in addition to cellular defense. Microbiol Mol Biol Rev 77, 53-72.

Wickham, H. (2016). ggplot2: elegant graphics for data analysis. Springer. 